\title{
THE EFFECTS OF EMPLOYEE VOICE, PERCEIVED \\ LEADERSHIP INTEGRITY, AND WORK-RELATED CURIOSITY ON COUNTERPRODUCTIVE MEETING BEHAVIORS
}

\author{
Foluso Philip Adekanmbi $₫$ \\ foladex12@yahoo.com \\ Wilfred Isioma Ukpere ${ }^{1}$ \\ ${ }^{1}$ Department of Industrial Psychology and People Management \\ College of Business \& Economics \\ University of Johannesburg \\ Auckland Park, South Africa, PO Box 524, 2006
}

$\triangle$ Corresponding author

\begin{abstract}
This study assesses the effects of employee voice, perceived leadership integrity, and work-related curiosity on counterproductive meeting behaviors within Nigeria's work organizations. The study's sample was taken from nine work organizations in Lagos and Oyo States of Nigeria. The nine work organizations were selected from Nigeria's financial, manufacturing, and service industries. These work organizations are Guarantee Trust Bank Plc, First City Monument Bank Plc, Full Range Microfinance Bank Limited, Seven-up Bottling Company Plc, Isoglass Industries Nigeria Limited, Atlantic Textile Company, Pixels Digital Services Limited, Pacesetters transport Services Limited, and IBFC Alliance Limited. Nevertheless, this paper has applied a cross-sectional survey approach, of which the present researcher randomly disseminated the survey forms (questionnaires). However, out of 450 questionnaires, 432 were fit for research and analyzed with statistical packages for social sciences (SPSS vs. 27). The current results established significant joint and independent negative effects of employee voice, perceived leadership integrity, and work-related curiosity on counterproductive meeting behaviors within Nigeria's work organizations. The management of work organizations ensures adequate and consistent encouragement of employee voice by allowing employee expressions, suggestions, making the employee feel important, and rendering listening ears. They should also train and inspire leaders who stimulate and exemplify leadership integrity. Furthermore, the management of work organizations should inspire employee curiosity as it relates to their work.

Keywords: Voice, honesty, curiosity, meetings, Nigeria.
\end{abstract}

DOI: $10.21303 / 2504-5571.2021 .002168$

\section{Introduction}

The ability to research and deliberate solutions to problems, come up with fresh ideas, encourage employee participation, and improve organizational efficiency puts meetings in a vital spot. Hence, investigating meetings is essential to organizations as their role in overall efficiency and employee well-being cannot be overemphasized [1]. Notably, the importance of meetings affects work behaviors and relationships when the sessions are over. [2, 3] suggested that as many as half of numerous meetings, held in work organizations, are noted poor quality. Many meetings are repeatedly called to achieve the aforementioned purposes that should have been completed in the former sessions [4]. To ascertain issues, adversely influencing meeting outcomes, scholars have initiated a look into the influence of counterproductive meeting behaviors (CMBs) on work organizations. They have found such detrimental to the progress of work organizations $[5,6]$. Counterproductive meeting behaviors are exhibited by meeting attendee(s) within an organization, which cause impairment in the meeting or hinder its progress [7]. Research has noted some forms of counterproductive meeting behaviors. They are persistent lateness, disrespectful during meetings (for example, having side chats or conversing with irrelevant topics), concealing vital information and suggestions, and blaming other attendees [5].

Employee voice in an organizational context may be described as the extent to which employees are stimulated, feel, and able to communicate their opinions [8]. It involves behavior and 
communication that progress the phases of the work setting. However, employee voice does not simply disapprove of the current situation; instead, it proposes beneficial changes for the employees, workplace, or both [9]. Furthermore, leadership behavior plays a central part in stimulating organizational performance [10]. Integrity has been more precisely acknowledged as an ethical value with transparency, fairness, and consistency; it can also be seen as personal or organizational value $[11,12]$. [11] further opined that the personal value of integrity is frequently narrowly aligned to ethics, a lot that at times it substitutes for an individual's moral character; as a leader with integrity is seen one who consistently abides by ethical standards. Hence, such value influences the behavior of followers within a work organization. Curiosity can be termed a yearning for new ideas, knowledge, and solving problems [13]. Recent studies have shown the necessity for improving curiosity on the work floor as it positively predicts job performance and workers' behavior [14, 15].

Employee voice, perceived leadership integrity, and work-related curiosity are factors that influence job performance, employee behaviors, and organizational achievements [9, 11, 15]. Hence, research on their impacts on employer behavior, such as counterproductive meeting behavior within Nigeria's work organizations, will not only add to the literature but remain relevant for human resources management practices and employment relations within Nigeria's work organizations.

\section{1. Employee Voice and Counterproductive Meeting Behavior}

As the workplace has developed into a more team-intensive setting, scholars have focused on studying employee relations within the workplace setting to profit from improved employee voice [16]. Following the increased importance of interdependence in achieving work duties, workplace meetings allow employees to express their feelings within the work organization. So, the successful usage of these meetings will enable employees to use their voices. [9, 17] suggested that a business set up a positive and inspiring work environment to air the voice freely. [18] concluded that encouraging employee voice may produce positive employee behaviors and valuable developments for the organizations, such as enhanced organizational decision-making and successful meetings where work issues are solved. Furthermore, organizations encourage employee voice experience outcomes, such as organizational commitment [19], job satisfaction [20], and employee engagement [21, 22]. According to [9], employee voice is negatively related to counterproductive meeting behaviors. They indicated that as employee voice decreases, counterproductive meeting behaviors increase. Therefore, the following is hypothesized:

H1: Employee voice significantly influences counterproductive meeting behavior among employees within Nigeria's work organization.

\section{2. Perceived Leadership Integrity and Counterproductive Meeting Behavior}

Leadership integrity in the workplace has usually been branded a positive variable, grounded in charismatic and transformational leadership styles. Workers or followers are more ready to trust leaders to influence their behaviors and attitudes [23]. Perceived leadership integrity can also be termed the perceived alliance between a leader's words and actions. Hence, it is the perception that a leader exhibits behaviors consistent with their words concerning priorities, leadership style, value, and expectation [24]. Leadership integrity promotes a work environment where employees are esteemed. Employees tend to achieve their goals more and meet their psychological needs in a work environment where leadership integrity flourishes. Through leaders' integrity within a workplace, employees can actively contribute to themselves and the organization by exhibiting several positive behaviors [25]. Employees who perceive their leaders to have integrity tend to engage in positive behaviors than those who less perceive their leaders as such [26]. Their research [27] established a negative correlation between perceived leadership integrity and counterproductive meeting behaviour. Also, [28]'s investigation found that perceived leadership integrity notably and negatively impacts counterproductive meeting behavior. [29] opined that leadership integrity increases employees' involvement in an organization, resulting in more exhibition of positive behaviors from the employees. Employees are always eager to display positive behaviors, such as citizenship behaviors, cooperating and collaborating with colleagues, exhibiting can-do attitudes, problem-solving abilities, confidence, dependability, among others, as they perceive the quality 
of leadership integrity within their workplace [30]. Reinforced by the researches on perceived leadership integrity and counterproductive meeting behaviour, mentioned above, this paper hypothesized that:

H2: Perceived leadership integrity significantly impacts counterproductive meeting behavior among employees within Nigeria's work organization.

\section{3. Work-related Curiosity and Counterproductive Meeting Behavior}

Curiosity is linked to openness for new ideas, intelligent engagement, and the need for cognition. Hence, curious individuals in the workplace inherently love the practice of new learnings, thinking, and discoveries [31]. Furthermore, curiosity is a precursor of systematic findings [32] and is taken as a drive to be strengthened by work organizations and instructors [33]. Curiosity is a drive that galvanizes individuals towards exploratory action and thinking modes [34, 35]. Moreover, work-related curiosity influences behavior disorders (substance abuse), particular workplace deviant behaviors, and anti-social behaviors [13]. [31] opined that counterproductive behaviour, such as counterproductive meeting behaviour, is significantly avoided or discouraged by individuals who exhibit more work-related curiosity. Such meetings serve as platforms for them to constantly express their drive for acquiring new knowledge and project solutions/discoveries they have noted through their drive. To know the effect of work-related curiosity on counterproductive meeting behaviors within Nigeria's work organizations, the current investigation has proposed the following statement:

H3: Work-related curiosity significantly impacts counterproductive meeting behavior among employees within Nigeria's work organization.

Furthermore, the above literature review stimulated the hypothesis, stated below:

H4: There is a joint influence of employee voice, perceived leadership integrity, and work-related curiosity on counterproductive meeting behaviors among employees within Nigeria's work organizations.

This paper aims to increase the literature by examining the effects of employee voice, perceived leadership integrity, and work-related curiosity on counterproductive meeting behaviors; and to suggest an applied model to significantly dissuade and decrease counterproductive meeting behaviors within Nigeria's work organizations.

\section{Methods}

The current study, which was carried out in April 2021, adopted a cross-sectional survey approach. Survey forms were distributed amongst participants to test the current study hypotheses and gather data about their views on employee voice, perceived leadership integrity, work-related curiosity, and counterproductive meeting behaviors in their work organizations of study. Questionnaires were handed to 450 employees from eight work organizations in Lagos and Oyo States of Nigeria. Nine (9) work organizations were selected from Nigeria's financial, manufacturing, and service industries. These work organizations are Guarantee Trust Bank Plc, First City Monument Bank Plc, Full Range Microfinance Bank Limited, Seven-up Bottling Company Plc, Isoglass Industries Nigeria Limited, and Atlantic Textile Company Pixels Digital Services Limited, Pacesetters transport Services Limited, and IBFC Alliance Limited. Data, retrieved from participants, were analyzed and presented in tables. Nevertheless, the current study respects the ethical matters, related to gathering, quantifying, and keeping private data. So, this investigation stimulated voluntary participation. Altogether, 432 questionnaires were recovered and considered fit to use. The data retrieved was cleansed and analyzed with the statistical package for social sciences (SPSS v 27). A multiple regression analysis was used to test the stated hypotheses. The present investigation piloted reliability analyses in achieving the local reliability of the measure.

\section{1. Instrumentation}

In this study, the survey included different subdivisions:

Section A - Employees' demographics

This section has the respondents' demographics, like age, gender, religion, marital status, education qualification, and job level.

Section $B$ - Employee voice scale (EVS) 
This section of the questionnaire had a six-item measuring scale, modified from [36] to quantify the perceived employee voice among participants. This instrument rates items on a 7-point Likert scale, ranging from 1 (Strongly Disagree) to 7 (Strongly Agree). The developer of this scale indicated a Cronbach's alpha reliability coefficient of 0.95 , whereas the current study has reported a Cronbach's Alpha reliability of 0.91 .

Section $C$ - Perceived leadership integrity scale (PLIS)

This paper adopted a short form of the Perceived Leadership Integrity Scale [37] to measure the respondents' perceived leadership integrity within their work organizations. This measuring tool has nine items and a 4-point Likert response format, reaching " $1=$ Never" to " $4=$ Every Time". The instrument developer specified a Cronbach's alpha reliability coefficient of 0.95 , and in the current study, a Cronbach's Alpha reliability of 0.91 was attained.

Section D: Work-related curiosity scale (W-RCS)

This section measures the respondents' perception of work-related curiosity within their work organizations; through a questionnaire, developed by [14]. This measure has ten items and a 7-point Likert response format, reaching " $1=$ Totally Disagree" to " $5=$ Totally Agree". [14] noted a Cronbach's alpha reliability coefficient of 0.86 , and in the current investigation, a Cronbach's alpha reliability of 0.90 was achieved.

Section $E$ - Counterproductive meeting behaviors scale (CMBS)

This paper measured employees' counterproductive meeting behaviors within their work organizations using a ten-item measure modified from a previous study [38]. Items were appraised on a 5-point Likert-type scale, varying from 1 (Strongly Disagree) to 5 (Strongly Agree). [38] indicated a 0.83 reliability coefficient for the scale. But, in this paper, the reliability coefficient is 0.88 .

The Statistical Package for Social Sciences (SPSS version 27) was used to analyze data, retrieved in this study. Nevertheless, this paper conducted a pilot investigation to identify any likely problems beforehand and validate the scale's effectiveness.

\section{Results}

The results from the data, analyzed in the current investigation, are shown in Table $\mathbf{1 .}$

Table 1

Demographics of the study's participants

\section{Characteristics}

Age

Gender

Work Experience

Job level

Category
$20-30$
$31-40$
$41-50$
Total
Male
Female
Total
1-3 years
4-6 years
7-10 years
above 10 years
Total
OND/HND
BTech/BSc.
MTech/MSc.
Total
Junior
Intermediate
Senior
Total

Frequency
145
218
69
$\mathbf{4 3 2}$
227
205
$\mathbf{4 3 2}$
128
191
95
18
$\mathbf{4 3 2}$
94
201
137
$\mathbf{4 3 2}$
87
215
130
432

Percent (\%)
33.6
50.5
16.0
$\mathbf{1 0 0 . 0}$
52.5
47.5
$\mathbf{1 0 0 . 0}$
29.6
44.2
22.0
4.2
$\mathbf{1 0 0 . 0}$
21.8
46.5
31.7
$\mathbf{1 0 0 . 0}$
20.1
49.8
30.1
100.0

Source: Author's fact-finding 
Table 1 shows that 145 participants were 20-30 years old, 218 were 31-40 years old, and 69 respondents were $41-50$ years old. Moreover, the table indicates that 227 participants were male, whereas 205 were female. The grouping of participants by work experience meant that more respondents had 4-6 years of work experience (191; 44.2\%) next, respondents who had 1-3 years of work experience $(128 ; 29.6)$, and participants with $7-10$ years work experience $(95 ; 22.0 \%)$, while the least respondents had above 10 years work experience $(18 ; 4.2 \%)$. Furthermore, the findings showed that $94(21.8 \%)$ participants were Ordinary National Diploma/Higher National Diploma holders, 201 (46.5\%) were Bachelor of Technology/Bachelor of Science licensed, and 137 (31.7 \%) were Master of Technology/Master of Science holders. Besides, the current results further included that 87 respondents were on junior job level, 215 on an intermediate level, and 130 respondents on senior job level.

\section{1. Inferential Statistics}

To make inferences in the current investigation, a multiple linear regression analysis was used.

Table 2

Multiple regressions, presenting the joint impact of employee voice, perceived leadership integrity, and workrelated curiosity on counterproductive meeting behaviors within Nigeria's work organizations

\begin{tabular}{cccccc}
\hline Model & R & R-squared & Adjusted R-squared & F & Sig \\
\hline 1 & $0.982^{\mathrm{a}}$ & 0.964 & 0.963 & 3776.33 & $0.000^{\mathrm{b}}$
\end{tabular}

Predictors: (Constant), Perceived Leadership Integrity, Employee Voice, Work-Related Curiosity.

Table 3

Coefficients of the predictors of counterproductive meeting behavior

\begin{tabular}{|c|c|c|c|c|c|c|c|c|c|c|}
\hline \multirow{2}{*}{ Influencers } & \multirow{2}{*}{ B } & \multirow{2}{*}{$\beta$} & \multirow{2}{*}{$\mathbf{t}$} & \multirow{2}{*}{ Sig } & \multicolumn{2}{|c|}{$\begin{array}{c}95.0 \% \text { Confidence Inter- } \\
\text { val for B }\end{array}$} & \multirow{2}{*}{$\mathbf{R}$} & \multirow{2}{*}{$\mathbf{R}^{2}$} & \multirow{2}{*}{ F $(3,431)$} & \multirow{2}{*}{$\mathbf{P}$} \\
\hline & & & & & $\begin{array}{l}\text { Lower } \\
\text { Bound }\end{array}$ & $\begin{array}{l}\text { Upper } \\
\text { Bound }\end{array}$ & & & & \\
\hline (Constant) & 58.311 & - & 194.349 & 0.000 & 57.721 & 58.900 & \multirow{4}{*}{0.982} & \multirow{4}{*}{0.964} & \multirow{4}{*}{3776.33} & \multirow{4}{*}{$<0.01$} \\
\hline Employee Voice & -0.125 & -0.086 & -5.160 & 0.000 & -0.173 & -0.077 & & & & \\
\hline $\begin{array}{l}\text { Work-Related } \\
\text { Curiosity }\end{array}$ & -0.491 & -0.751 & -39.806 & 0.000 & -0.515 & -0.467 & & & & \\
\hline $\begin{array}{l}\text { Perceived Leader- } \\
\text { ship Integrity }\end{array}$ & -0.313 & -.189 & -12.119 & 0.000 & -0.364 & -0.262 & & & & \\
\hline
\end{tabular}

Dependent Variable: Counterproductive Meeting Behavior

Table 2 showed that employee voice, perceived leadership integrity, and work-related curiosity significantly, jointly, and negatively influence employees' counterproductive meeting behaviors within Nigeria's work organizations $(\mathrm{R}=.982, \mathrm{R} 2=.964, \mathrm{~F}=3776.33, \mathrm{p}<.01)$. The value $\mathrm{p}$ is adequate. These findings indicated that employee voice, perceived leadership integrity, and work-related curiosity significantly, jointly, and negatively influenced a $98.2 \%$ variance in counterproductive meeting behavior within Nigeria's work organization. Thus, the hypothesis is confirmed that there is a joint influence of employee voice, perceived leadership integrity, and work-related curiosity on counterproductive meeting behaviors among employees within Nigeria's work organizations.

Furthermore, the model, presented in Table 3, specifies that employee voice significantly and negatively impacts employees' counterproductive meeting behaviors within Nigeria's work organizations at $\beta=.086, t=5.160 ; p<0.01$. The value $p$ is sufficient. So, this paper shows that employee voice contributed about $8.6 \%$ influence on variance in employees' counterproductive meeting behaviors within Nigeria's work organizations. Thus, the stated hypothesis, 
namely, employee voice significantly influences counterproductive meeting behavior among employees within Nigeria's work organization, is confirmed. Similarly, the current findings show that perceived leadership integrity significantly and negatively affects the variance in employees' counterproductive meeting behaviors within Nigeria's work organizations at $\beta=.751$, $\mathrm{t}=39.806 ; \mathrm{p}<0.01$. The value $\mathrm{p}$ is adequate. So, this paper suggests that perceived leadership integrity contributed about $75.1 \%$ influence on the change in employees' counterproductive meeting behaviors within Nigeria's work organizations. Therefore, the stated hypothesis is established: perceived leadership integrity significantly impacts counterproductive meeting behavior among employees within Nigeria's work organization. Also, Table 3 stipulates that work-related curiosity significantly and negatively influences employees' counterproductive meeting behaviors within Nigeria's work organizations at $\beta=0.189, t=12.119 ; \mathrm{p}<0.01$. The value $\mathrm{p}$ is enough. So, this paper shows that work-related curiosity contributed about $18.9 \%$ influence on variance in employees' counterproductive meeting behaviors within Nigeria's work organizations. So, the stated hypothesis, namely, work-related curiosity significantly impacts counterproductive meeting behavior among employees within Nigeria's work organization, is confirmed.

\section{Discussion}

The current results revealed that employee voice significantly and negatively influences counterproductive meeting behaviors within Nigeria's work organizations. This position infers that the more employee voice is encouraged within Nigeria's work organization, the less the employees exhibit counterproductive meeting behaviors. This paper corroborates [18]. They concluded that boosting employee voice may produce positive employee behaviors and valuable developments for the organizations, such as enhanced organizational decision-making and successful meetings where work issues are solved. It also supports [9]'s view that employee voice is negatively related to counterproductive meeting behaviors. They indicated that as employee voice decreases, counterproductive meeting behaviors increase.

Likewise, the current results have established that perceived leadership integrity significantly and negatively predicts counterproductive meeting behaviors among employees within Nigeria's work organizations. This position implies that employees within Nigeria's work organizations are deterred from engaging in counterproductive meeting behaviors the more they perceive their leaders as having integrity. The current results support [26], which opine employees who perceive their leaders to have integrity tend to engage in positive behaviors than those who less perceive their leaders as such. These results also corroborate the study of [27], which established a negative relationship between perceived leadership integrity and counterproductive meeting behavior. This paper also confirms [28]'s view that perceived leadership integrity significantly and negatively impacts counterproductive meeting behavior.

Furthermore, this paper posits that work-related curiosity significantly and negatively influences counterproductive meeting behaviors among employees within Nigeria's work organizations. Thus, the more curious employees within Nigeria's work organizations are regarding their work, the less they tend to exhibit counterproductive meeting behaviors. This paper, hence, confirms the position of [31], who opined that counterproductive behaviour, such as counterproductive meeting behaviour, is significantly avoided or discouraged by individuals who exhibit more work-related curiosity. Such meetings serve as platforms for them to constantly express their drive to acquire new knowledge and project solutions/discoveries, noted through their campaign. The current investigation also supports [13], as they stressed that work-related curiosity predicts particular workplace deviant behaviors and anti-social behaviors.

According to the current findings, this paper has achieved the study's aim: to suggest a practical model to significantly deter and decrease counterproductive meeting behaviors within Nigeria's work organizations. Hence, the model in Fig. 1 is below. 


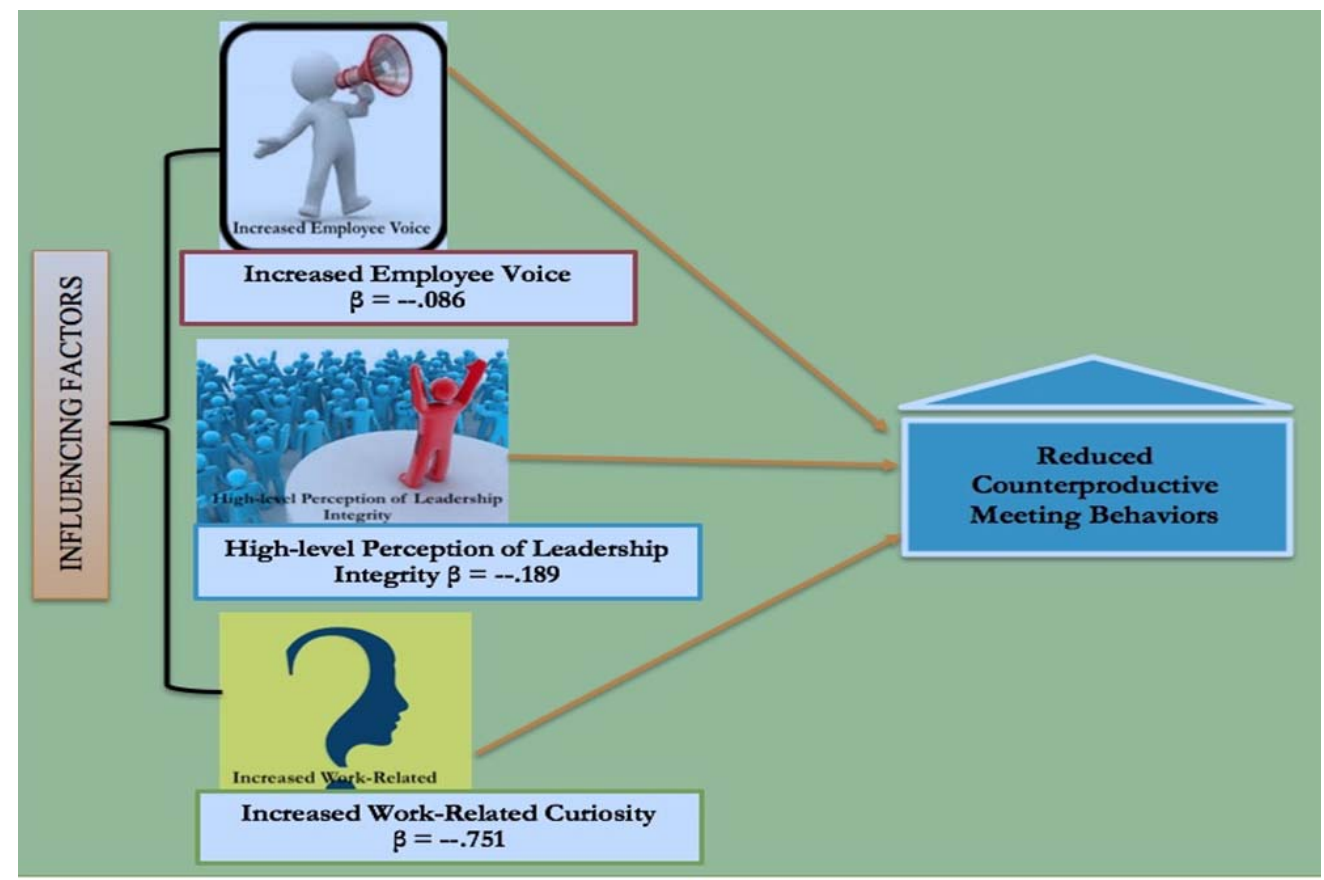

Fig. 1. A practical model to significantly deter and decrease counterproductive meeting behaviors within Nigeria's work organizations. Source: Author's findings

Research limitations. The current results are with some limitations. Firstly, the recent sample was restricted to the employees across the Lagos and Ibadan cities of Lagos and Oyo States, Nigeria. Hence, a future investigation should look into employees in other regions and States of Nigeria. This will ensure the generalizability of the findings. Second, the current research adopted a cross-sectional survey design.

The prospects for further research. Thus, future studies need to use an in-depth qualitative inquiry to operationalize further the concepts, linked to unproductive behaviors.

\section{Conclusion}

The current study concludes that employee voice, perceived leadership integrity, and work-related curiosity significantly, jointly, independently, and negatively influence counterproductive meeting behaviors within Nigeria's work organizations. Thus, these specified factors have been proven to predict counterproductive meeting behaviors within Nigeria's work organizations.

The hypothesis - employee voice significantly influences counterproductive meeting behavior among employees within Nigeria's work organization, is confirmed. Also, the stated hypothesis is established: perceived leadership integrity significantly impacts counterproductive meeting behavior among employees within Nigeria's work organization. In addition, the stated hypothesis, namely, work-related curiosity significantly impacts counterproductive meeting behavior among employees within Nigeria's work organization, is proved. Furthermore, the hypothesis that there is a joint influence of employee voice, perceived leadership integrity, and work-related curiosity on counterproductive meeting behaviors among employees within Nigeria's work organizations is proved.

However, the following suggestions are beneficial:

- This paper recommends that management of work organizations ensure adequate and consistent encouragement of employee voice by allowing employee expressions, suggestions, making the employee feel important, and rendering listening ears. Furthermore, the management of work organizations should inspire employee curiosity as it relates to their work

- Managers who show integrity in leadership become models of exemplary behavior and tend to encourage positive workplace behaviors amongst their employees. Hence, the current study 
recommends that management of work organizations trains and inspires leaders who stimulate and exemplify leadership integrity.

- Moreover, for further investigation, this paper recommends qualitative empirical studies better to understand the employees' perception of counterproductive meeting behaviors.

\section{Acknowledgment (S):}

The current author acknowledges the Department of Industrial Psychology and People Management, College of Business and Economics, University of Johannesburg, under Professor Wilfred Ukpere, in funding the current study and its publication.

\section{References}

[1] Rogelberg, S. G., Scott, C. W., Agypt, B., Williams, J., Kello, J. E., McCausland, T., Olien, J. L. (2013). Lateness to meetings: Examination of an unexplored temporal phenomenon. European Journal of Work and Organizational Psychology, 23 (3), 323-341. doi: http://doi.org/10.1080/1359432x.2012.745988

[2] Rogelberg, S. G., Allen, J. A., Shanock, L., Scott, C., Shuffler, M. (2010). Employee satisfaction with meetings: A contemporary facet of job satisfaction. Human Resource Management, 49 (2), 149-172. doi: http://doi.org/10.1002/hrm.20339

[3] Schell, A. (2010). Meeting culture in European companies. European business meeting culture. Munich, Germany: Schell Marketing Consulting.

[4] Allen, J. A., Rogelberg, S. G., Scott, J. C. (2008). Mind your meetings: Improve your organization's effectiveness one meeting at a time. Quality Progress, 41, 48-53. Available at: https://digitalcommons.unomaha.edu/psychfacpub/93

[5] Kauffeld, S., Lehmann-Willenbrock, N. (2012). Meetings matter: Effects of team meetings on team and organizational success. Small Group Research, 43 (2), 130-158. doi: http://doi.org/10.1177/1046496411429599

[6] Schulte, M. T., Hser, Y.-I. (2013). Substance Use and Associated Health Conditions throughout the Lifespan. Public Health Reviews, 35 (2). doi: http://doi.org/10.1007/bf03391702

[7] Lehmann-Willenbrock, N., Allen, J. A., Kauffeld, S. (2013). A Sequential Analysis of Procedural Meeting Communication: How Teams Facilitate Their Meetings. Journal of Applied Communication Research, 41 (4), 365-388. doi: http://doi.org/ 10.1080/00909882.2013.844847

[8] Allen, J. A., Rogelberg, S. G. (2013). Manager-Led Group Meetings. Group \& Organization Management, 38 (5), $543-569$. doi: http://doi.org/10.1177/1059601113503040

[9] Allen, J. A., Yoerger, M. A., Lehmann-Willenbrock, N., Jones, J. (2015). Would you please stop that!? The relationship between counterproductive meeting behaviors, employee voice, and trust. Journal of Management Development. 34 (10), $1272-1287$. doi: http://doi.org/10.1108/jmd-02-2015-0032

[10] Adeshipo, A. S., Harrison, C. (2018). Ethical leadership: An effective and efficient leadership approach for Nigeria's public sector. British Academy of Management Annual Conference 2018: Driving Productivity in Uncertain and Challenging Times, 567. Available at: https://research-portal.uws.ac.uk/en/publications/ethical-leadership-an-effective-and-efficient-leadership-approach

[11] Rossouw, D., Van Vuuren, L. (2010). Business Ethics Southern Africa. Oxford University Press, 341.

[12] Palanski, M. E., Kahai, S. S., Yammarino, F. J. (2010). Team Virtues and Performance: An Examination of Transparency, Behavioral Integrity, and Trust. Journal of Business Ethics, 99 (2), 201-216. doi: http://doi.org/10.1007/s10551-010-0650-7

[13] Celik, P., Storme, M., Davila, A., Myszkowski, N. (2016). Work-related curiosity positively predicts worker innovation. Journal of Management Development, 35 (9), 1184-1194. doi: http://doi.org/10.1108/jmd-01-2016-0013

[14] Mussel, P., Spengler, M., Litman, J. A., Schuler, H. (2012). Development and Validation of the German Work-Related Curiosity Scale. European Journal of Psychological Assessment, 28 (2), 109-117. doi: http://doi.org/10.1027/1015-5759/a000098

[15] Mussel, P. (2012). Introducing the construct curiosity for predicting job performance. Journal of Organizational Behavior, 34 (4), 453-472. doi: http://doi.org/10.1002/job.1809

[16] Detert, J. R., Burris, E. R., Harrison, D. A., Martin, S. R. (2013). Voice flows to and around leaders: Understanding when units are helped or hurt by employee voice. Administrative Science Quarterly, 58 (4), 624-668. doi: http:// doi.org/10.1177/0001839213510151

[17] Kim, S., Ishikawa, J. (2020). Employee voice mechanisms, transformational leadership, group prototypicality, and voice behaviour: a comparison of portfolio career workers in Japan, Korea and China. Asia Pacific Business Review, 27 (1), $111-144$. doi: http://doi.org/10.1080/13602381.2021.1846963

[18] Morrison, E. W., Milliken, F. J. (2000). Organizational Silence: A Barrier to Change and Development in a Pluralistic World. The Academy of Management Review, 25 (4), 706-725. doi: http://doi.org/10.2307/259200 
[19] Farndale, E., Van Ruiten, J., Kelliher, C., Hope-Hailey, V. (2011). The influence of perceived employee voice on organizational commitment: An exchange perspective. Human Resource Management, 50 (1), 113-129. doi: http://doi.org/10.1002/hrm.20404

[20] Wood, S., de Menezes, L. M. (2011). High involvement management, high-performance work systems and well-being. The International Journal of Human Resource Management, 22 (7), 1586-1610. doi: http://doi.org/10.1080/09585192.2011.561967

[21] Purcell, J. (2014). Can employee voice and participation unlock employee engagement? Insights: Melbourne Business and Economics, 15 (1), 23-30.

[22] Ruck, K., Welch, M., Menara, B. (2017). Employee voice: An antecedent to organisational engagement? Public Relations Review, 43 (5), 904-914. doi: http://doi.org/10.1016/j.pubrev.2017.04.008

[23] Williams Jr, R., Raffo, D. M., Clark, L. A. (2018). Charisma as an attribute of transformational leaders: what about credibility? Journal of Management Development, 37 (6), 512-524. doi: http://doi.org/10.1108/jmd-03-2018-0088

[24] Simons, T. (2002). Behavioral integrity: The perceived alignment between managers' words and deeds as a research focus. Organization Science, 13 (1), 18-35. doi: http://doi.org/10.1287/orsc.13.1.18.543

[25] Michele Kacmar, K., Tucker, R. (2014). The Moderating Effect of Supervisor's Behavioral Integrity on the Relationship between Regulatory Focus and Impression Management. Journal of Business Ethics, 135 (1), 87-98. doi: http://doi.org/10.1007/ s10551-014-2464-5

[26] Guohao, L., Pervaiz, S., Qi, H. (2021). Workplace Friendship is a Blessing in the Exploration of Supervisor Behavioral Integrity, Affective Commitment, and Employee Proactive Behavior - An Empirical Research from Service Industries of Pakistan. Psychology Research and Behavior Management, 14, 1447-1459. doi: http://doi.org/10.2147/prbm.s329905

[27] Van Iddekinge, C. H., Roth, P. L., Raymark, P. H., Odle-Dusseau, H. N. (2012). The criterion-related validity of integrity tests: An updated meta-analysis. Journal of Applied Psychology, 97 (3), 499-530. doi: http://doi.org/10.1037/a0021196

[28] Hunter, W. F. J. R. (2014). The Role of Integrity and Personality in Counterproductive Work Behavior. Available at: https:// hdl.handle.net/10019.1/86570

[29] Veríssimo, J., Lacerda, T. (2015). The impact of CEOS' transformational leadership and ethical integrity on strategic orientation to corporate social responsibility. European Journal of Management Studies, 20 (2), 95-114. Available at: https://EconPapers.repec.org/RePEc:pjm:journl:v:xx:y:2015:i:2:p:95-114

[30] Kaiser, R. B., Hogan, R. (2010). How to (and how not to) assess the integrity of managers. Consulting Psychology Journal: Practice and Research, 62 (4), 216-234. doi: http://doi.org/10.1037/a0022265

[31] Mussel, P. (2010). Epistemic curiosity and related constructs: Lacking evidence of discriminant validity. Personality and Individual Differences, 49 (5), 506-510. doi: http://doi.org/10.1016/j.paid.2010.05.014

[32] Simonton, D. K. (2012). Quantifying creativity: Can measures span the spectrum? Dialogues in Clinical Neuroscience, 14 (1), 100-104. doi: http://doi.org/10.31887/dens.2012.14.1/dsimonton

[33] Goodwin, B. (2014). Research Says / Curiosity Is Fleeting, but Teachable. Available at: https://www.ascd.org/el/articles/curiosity-is-fleeting-but-teachable

[34] Kashdan, T. B., Silvia, P. J. (2009). Curiosity and interest: The benefits of thriving on novelty and challenge. Oxford Handbook of Positive Psychology, 2, 367-374. doi: http://doi.org/10.1093/oxfordhb/9780195187243.013.0034

[35] Harrison, S. H., Sluss, D. M., Ashforth, B. E. (2011). Curiosity adapted the cat: The role of trait curiosity in newcomer adaptation. Journal of Applied Psychology, 96 (1), 211-220. doi: http://doi.org/10.1037/a0021647

[36] Van Dyne, L., LePine, J. A. (1998). Helping and voice extra-role behaviors: evidence of construct and predictive validity. Academy of Management Journal, 41 (1), 108-119. doi: http://doi.org/10.2307/256902

[37] Whelan, T., Stoughton, J., Craig, S., Parry, K. (2014). A short-form of the perceived leadership integrity scale (sPLIS). Paper presented at the 29th Annual Conference of the Society for Industrial and Organizational Psychology. Honolulu.

[38] Lehmann-Willenbrock, N., Allen, J. A., Belyeu, D. (2016). Our love/hate relationship with meetings: Relating good and bad meeting behaviors to meeting outcomes, engagement, and exhaustion. Management Research Review. doi: http:// doi.org/10.1108/mrr-08-2015-0195

Received date 18.10.2021

(C) The Author(s) 2021

Accepted date 16.11.2021

Published date 30.11.2021

This is an open access article under the Creative Commons CC BY license

How to cite: Adekanmbi, F. P., Ukpere, W. I. (2021). The effects of employee voice, perceived leadership integrity, and work-related curiosity on counterproductive meeting behaviors. EUREKA: Social and Humanities, 6, 43-51. doi: http://doi.org/10.21303/ 2504-5571.2021.002168 